PROFESSIONAL PAPER

\title{
Agglomeration process in the fluidized bed, the effecting parameters and some applications
}

\author{
Hira Yuksel*, S. Nur Dirim \\ Department of Food Engineering, Ege University, 35100 Bornova, Izmir, Turkey \\ *Corresponding author: hirayuksel@gmail.com
}

Abstract

The agglomeration process has been commonly used to improve the functional properties of powder products to form larger agglomerates. Agglomeration provides a granular structure to powders, reduce the dusting and improving their characteristics, such as storage stability, wettability, dispersibility, and solubility. This process can be performed by different methods, one of which is fluidized bed agglomeration widely used in food processing since the agglomerates produced by this technique have high porosity, low density, and good mechanical resistance. At the same time, this process is influenced by many factors; e.g., inlet air temperature, air velocity, mixing rate, and properties of the binder agents. Inlet air temperature affects the mass and heat transfer; air velocity prevents caking and accelerates mass and heat transfer; mixing rate allows mixing the binder agent uniformly over the particles; and the properties of the binder agent, such as concentration and viscosity have an impact on the properties of the final product. These four factors should be well known and controlled so that the agglomerates produced have the desired properties. Furthermore, the use of fluidized bed agglomeration results in products that can be used in widespread areas and in high quantities, and this method also creates the opportunity to utilize excess foods not consumed.

Keywords: powders; agglomeration process; fluidized bed agglomeration; particle size; powder properties.

\section{Introduction}

In the agglomeration process, particles of larger size are obtained by connecting small particles with each other without compromising their properties. This process is applied in many fields, including pharmaceutical, food and chemical industries (Iveson et al, 2001; Litster and Ennis, 2004; Palzer, 2011; Saleh and Guigon, 2009). Agglomeration can be applied to a wide variety of powders; e.g., organic, biological, amorphous, crystalline, spherical, smooth, and irregular (Palzer, 2011). In recent years, agglomeration has been extensively used to improve the functional properties of powders, such as their flowability, wettability, and solubility. Depending on the functional property desired to be developed for powder products, different agglomeration methods are employed; e.g., fluidized bed, drum, steam jet, and high shear agglomeration. The agglomeration method applied affects the structure and end-use properties of the agglomerates (Hafsa et al, 2015). In general, the agglomeration process is divided into two groups as dry or wet agglomeration according to whether a binder is used (Schuchmann, 1995). Compared with dry agglomeration, wet agglomeration provides better control of particle homogeneity, bulk density, and compactibility (Burggraeve et al, 2013). In wet agglomeration, the addition of water primarily results in adhesion forces between the particles; the water is dispersed on the particles by the mixing process and the increased particle movements promote the increasing of the particle size. With the final drying process, the stability of the agglomerates is ensured. One of the most commonly used agglomeration methods is fluid bed agglomeration due to the effect of hot air, pulverized water or binder solution, and very fast mass and heat transfer (Ziyani and Fatah, 2014).

\section{Flow In Fluidized Beds}

In fluids with low velocity, such as air, the particles remain stationary. As the fluid velocity is increased, the pressure drop calculated according to the Ergun equation in formula (1) increases. The minimum velocity for fluidization is defined as the velocity at which a particle starts to move. When, air velocity is further increased, which gradually reduces the pressure drop (Geankoplis, 2003).

$$
\frac{\Delta \mathrm{P}}{\Delta \mathrm{L}}=\frac{150 \mu \mathrm{v} \prime}{\phi^{2} \mathrm{D}_{\mathrm{p}}{ }^{2}} \frac{(1-\epsilon)^{2}}{\epsilon^{3}}+\frac{1.75 \rho\left(\mathrm{v}^{\prime}\right)^{2}}{\phi \mathrm{D}_{\mathrm{p}}} \frac{(1-\epsilon)}{\epsilon^{3}}
$$

where $\Delta \mathrm{P}$ is the pressure drop $(\mathrm{Pa}), \Delta \mathrm{L}$ is the height of bed (m), $\mathrm{V}$ is the velocity of fluid $(\mathrm{m} / \mathrm{s}), \varepsilon$ is porosity (the ratio of volume of voids in the bed to the total volume of the bed), $\mathrm{q}$ is the density of fluid $\left(\mathrm{kg} / \mathrm{m}^{3}\right), \mu$ is the viscosity of fluid $(\mathrm{kg} / \mathrm{m} . \mathrm{s})$, $\mathrm{D}_{\mathrm{p}}$ is the effective mean diameter of the particles $(\mathrm{m})$, and $\phi$ is the shape factor.

The shape factor used in formula (1) is described as the ratio of the surface area of any sphere having the same volume as the particle to the actual surface area of the particle as given in formula (2). Food products generally have irregular shapes; therefore, the use of the shape factor based on $(\phi D p)$ is more 
accurate. The effective mean diameter $\left(\mathrm{D}_{\mathrm{p}}\right)$ can be approximately determined by sieve analysis (Geankoplis, 2003).

$$
\phi=\frac{S_{p}}{V_{p}}
$$
particle.

where $\mathrm{S}_{\mathrm{p}}$ is the surface area and $\mathrm{V}_{\mathrm{p}}$ is the volume of the

The pressure drop is calculated using formula (3);

$$
\frac{\Delta \mathrm{P}}{\mathrm{L}_{\mathrm{mf}}}=\left(1-\epsilon^{\mathrm{mf}}\right)\left(\rho_{\mathrm{p}}-\rho\right) \mathrm{g}
$$

where $\mathrm{E}_{\mathrm{mf}}$ is porosity at minimum velocity and $\mathrm{q}_{\mathrm{p}}$ is the density of particle $\left(\mathrm{kg} / \mathrm{m}^{3}\right)$.

\section{Fluidized Bed Agglomeration}

Fluidized bed agglomeration (Figure 1) is widely used to improve the properties of milk powder, instant coffee, cocoa beverages or powders in the food industry (Palzer, 2011; Turchiuli et al, 2012). In this method, the movement of mass of powder with an upwardly directed air stream is provided and at the same time, a binder solution or water is sprayed onto the moving particles. In this process, several mechanisms, such as wetting, growing and drying of the particles take place. Fluidized bed agglomeration can be carried out using water or with a binding agent that can be sprayed onto the fluidized bed from the top or in a tangential direction (Ziyani and Fatah, 2014). During this process, the particles move close to each other and cohesive forces formed after collisions are increased by wetting. Binding agents used as a mixture of steam, liquid, or both are important because they allow the structure to remain stable and provide the desired physical and powder properties in agglomerates (Tikhonova et al, 2014). In the literature, there are studies on maltodextrin (Fuchs et al, 2006; Jinapong et al, 2008; Ziyani and Fatah, 2014), and lecithin (whey) and hydroxypropyl methylcellulose (gum arabic) solutions (Dadkhah and Tsotsas, 2014). Maltodextrin has the advantages of being highly soluble in water, having low viscosity, and not changing the color, odor or taste of food, whey is used as a good barrier against oxidation, and gum arabic is preferred because of its high solubility, low viscosity and emulsifying properties. There are many studies that examine the effects of the use of various binding agents on the physical and powder properties of agglomerates. For example, in an effort to examine how the hydroxypropyl cellulase concentration (HCP) (2-8\%), binder flow rate, atomization pressure, air velocity, and binder type affected the agglomerate growth mechanism and final product properties, it was concluded that the agglomeration process can be improved by the addition of the amount of binder since it is the main factor that controls the growth process. In addition, although the bed was unable to provide a certain moisture threshold, agglomerates were more easily broken down by the effect of air velocity (Bouffard et al, 2005). It is known that functional properties, such as wettability of the powder product can also be improved by adding gum arabic or maltodextrin (Ghosal, 2010). In addition, during the agglomeration process, the addition of a binder helps the growth and fluidization of the particles (Barbosa-Canovas, 2005). Finally, the particles are dried and discharged from the fluidized bed.

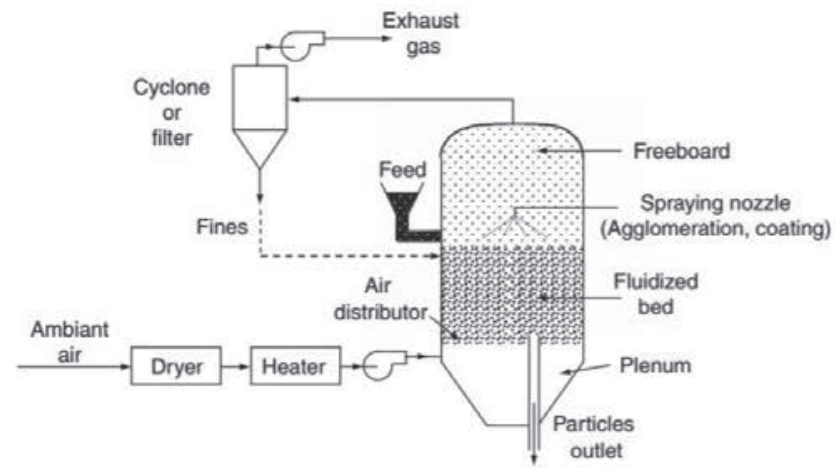

Figure 1. The schematic presentation of agglomeration using fluidized bed equipment (Turchiuli, 2013).

Agglomeration is a complicated process since it is affected by several factors, such as air velocity, temperature, moisture content, and properties of the binding agents (Saleh and Guigon, 2009; Turchiuli et al, 2005). The factors influencing this process should be well known and understood to offer simple solutions to the problems that may arise and increase productivity and time and cost efficiency. By controlling certain parameters, improved powder properties can be obtained. In addition, using appropriate values for the affecting parameters, such as air velocity, inlet air, and temperature, the process time can be reduced due to the accelerated mass and heat transfer, which also minimizes the cost of the process.

\section{The Factors Affecting the Fluidized Bed Agglomeration Process}

In the agglomeration process, it is important to know the following factors because they affect the properties of the final product:

Inlet air temperature is known as an important parameter since during the agglomeration process, the fluidizing air acts as a heat and moisture carrier. The particles absorbing heat with water evaporation from the surface can cause temperature fluctuations. In order to solve this problem, the product to be agglomerated in the fluidized bed can be preheated. In addition, the heat transfer is slowed down by low air temperature to prolong the process time. For this reason, it is not desirable to use a very low air temperature; however, if the air temperature is too high, then sufficient wetting cannot be achieved to bring the particles together, and the resulting extremely dry conditions would lead to the failure of the agglomeration process. In a study investigating the effects of parameters, the fluidized bed was operated under the following conditions; air temperature $60-80^{\circ} \mathrm{C}$, air velocity $0.51-0.67 \mathrm{~m} \mathrm{~s}^{-1}$, and binder flow rate 1.2-2.0 $\mathrm{mL} \mathrm{min-1.} \mathrm{An} \mathrm{aqueous} \mathrm{carboxymethyl} \mathrm{cellulose} \mathrm{solu-}$ tion was used as the liquid binder to examine the effect on the mean particle diameter, process yield, and moisture content. It was reported that the largest particle size was achieved when 
the air temperature was between 64 and $74^{\circ} \mathrm{C}$ (Machado et al, 2014).

Air velocity being high leads to the rapid movement of the particles, which in turn accelerates the mass transfer and reduces the risk of caking (Liu, 2000; Palzer, 2007). However, when the air velocity is too high, the powders may not be able to form a suitable medium for fluidization due to dispersion, or the agglomerates formed may be broken down (Machado et al, 2014). If the air velocity is low, the particles start to collapse, thus the agglomeration process would not be successful (Palzer, 2005). Rayo et al. (2015) performed fluidized bed agglomeration in green banana flour, which is sensitive to temperature with poor wettability and dispersibility due to its high starch content. The authors used sodium alginate as the binder and selected the temperature as $95^{\circ} \mathrm{C}$ and the air velocity as $1.2-1$ $\mathrm{m} / \mathrm{s}$, and the process time was 50 minutes. The agglomerated product was found to have reduced moisture content, increased mean particle diameter, and irregular shape. It was also reported that the wettability time of the agglomerates decreased, and the resulting low viscosity improved the permeability.

Moisture content affects the flow properties of powders, and thus has an important influence on the binding mechani$\mathrm{sm}$. If the water/binder solution sprayed during the process is homogeneously dispersed, all particles will have the same moisture content. It is well known that the initial temperature of a powder product being too high shortens the residence time in the bed due to the rapid mass and heat transfer. At the same time, when the particles are not wet enough to form a bond for agglomeration, the excessive amount of primary powders increase in the final product. However, if the initial moisture content is too high, then very wet and sticky particles would be obtained (Palzer, 2007).

Mixing rate affects the size of the agglomerates because it determines whether the water or binder solution added is homogeneously dispersed on the particles during agglomeration. This parameter promotes heat transfer and helps to create the desired structure. Inappropriate mixing may prevent the formation of agglomerates and result in an increase in the amount of powder, while in some other cases cause collapse due to the excessively wet structure (Saad et al, 2011). As a result, the efficiency of the process is negatively affected.

The properties of the binding agents, such as gum arabic, maltodextrin, starch, and alginate that are frequently used in studies (Knight, 2001) can help achieve the desired functional properties of the powder products by contributing to the growth of the particles and improvement of fluidity (BarbosaCanovas et al, 2005). In addition, the concentration, viscosity, mechanical properties, and type of the binding solution affect the reconstitution properties, and the relation between these parameters also has an impact on the efficiency of the agglomeration process (Ghosal, 2010). Initially, binder solutions are coated with a thin layer of powder products having a large surface area, resulting in agglomerates with an increased particle size depending on the concentration of the solution. This continues until a critical concentration is reached depending on the content and structure of the product, and when the agglomerate weight exceeds the strength of the bonds, it causes the breakdown of the agglomerates (Hemati et al, 2003). For example, in a previous study, the addition of polyvinylpyrrolidone (PVP) and acacia gum at $1-4 \%$ resulted in an increase in the particle size by 225 to $466 \mu \mathrm{m}$ and 285 to $531 \mu \mathrm{m}$, respectively, and the particle size decreased at concentrations above 4\%. However, the addition of gelatin up to $2 \%$ increased the particle size, while at 3-4\% concentration, a decrease in size growth was observed (Rohera and Zahir, 1993). This confirms that low binder solution concentrations resulted in more irregular and smaller agglomerates (Planinsek et al, 2000; Rohera and Zahir, 1993; Tuske et al, 2005). The viscosity and type of binder solution is also an important feature that affects the size of the agglomerates. At high viscosity, it is not possible to achieve the desired size due to the sprayed water droplets being very large (Seo et al, 2002). In another study, two different combinations of solid-liquid systems were used and were reported to affect the growth of pre-agglomerates. For agglomerates produced with a low-viscosity (1 mPa.s) solution ( $9 \mathrm{wt} \%$ liquid), the liquid layer was approximately $9.5 \mu \mathrm{m}$ thick on a $282-\mu \mathrm{m}$ particle, whereas for those obtained using a high-viscosity solution (84.7 mPa.s) (10 wt \% liquid), the liquid layer was only $3.5 \mu \mathrm{m}$ thick on a $140-\mu \mathrm{m}$ particle. The reason was explained as that the liquid with high viscosity could not migrate to the surface of the agglomerates and caused the formation of a thick liquid film whereas the low-viscosity binder liquid that migrated to the surface prevented roughness of the surface (Kumar et al, 2017). Hence, by using low-viscosity liquids, more spherical agglomerates can be produced by increasing air velocity or bed height. In addition, the type of binder depends on the process conditions and the structure of the food. Maltodextrin, for example, has high solubility in water and low viscosity, while at the same time it does not affect sensory properties, such as flavor, odor, or color (Barbosa-Canovas et al, 2005), while gelatin addition leads to high hardness and slow disintegration.

From the literature review given above, it can be stated that despite having several advantages, such as improving the functional properties of the powdered product, the use of a binder solution also creates adverse conditions; including sticky particles surface, low particle fluidization, and differences in the final moisture content of agglomerates. For example, when the sprayed binder solution is not dispersed in equal amounts over a powder product, the conditions for bringing the particles together and for growth are not met. This is due to inhomogeneous fluidization, in which some particles containing a binder solution are fluidized to form the agglomerate form, while others are not able to reach a sufficient amount of the binder solution, and thus cannot form agglomerates and remain as primary particles (Burggraeve et al., 2013). This naturally reduces the amount of agglomerates obtained. In addition, when a small amount of binding agent is used, the agglomerates formed may not have the desired properties. If the concentration or amount of binder solution is too high, then the fluid bed may collapse since the products create a wet mass and cannot dry, which prevents fluidization. This indicates the importance of understanding and controlling the process parameters.

\section{Studies Related to Fluidized Bed Agglomeration}

Agglomeration is a process that is applied to improve properties, such as the final wettability and solubility of primary particles transformed into agglomerates (Dewettinck and Huyghebaert, 1998; Teunou and Poncelet, 2002); therefore, 
studies on the agglomeration of powders examine the processing conditions and changes in structural and functional properties.

Jinapong et al. (2008) investigated the drying of soya milk in a spray drier with the addition of maltodextrin [dextrose equivalent (DE) 14; 7-20.7\%] at different concentrations, followed by the agglomeration process. The researchers increased the particle size of the powders using pure water and water $(0 \%, 5 \%, 10 \%, 15 \%$, and $20 \%)$ containing maltodextrin at different concentrations, and they reported that the particle size varied between $116.95 \mu \mathrm{m}$ and $259.57 \mu \mathrm{m}$, which were higher than the size of the powders $(14.54 \mu \mathrm{m})$, indicating that the flow properties determined according to the HR ratio (Hausner ratio) and $\mathrm{CI}$ index (Carr index) were improved. The $\mathrm{CI}$ and HR ratios of the powders were 40 and 1.67 , respectively whereas for the agglomerates with maltodextrin $(0 \%, 5 \%, 10 \%$, $15 \%$, and $20 \%$ ), the CI index ranged from 18 to 33 and the HR ratio from 1.23 to 1.62 . The authors also observed that the agglomerates exhibited less adhesion, and that the bulk and tapped density values were 0.31 to $0.27 \mathrm{~g} / \mathrm{cm}^{3}$ higher compared to the powders $\left(0.21 \mathrm{~g} / \mathrm{cm}^{3}\right)$.

In another study, oil powders were obtained by the spray drying method were subjected to agglomeration with pure water and a maltodextrin solution. The researchers reported that the increase in the moisture content caused by the agglomeration process can be prevented by the addition of maltodextrin. The wettability time of the powders was reported as; 28 minutes for the spray-dried powder products, 2 seconds for powder products agglomerated with distilled water, and 61 seconds for those agglomerated with the maltodextrin solution. The lowest bulk density and tapped density values were observed in agglomerates containing pure water, and the highest were obtained from the non-agglomerated powders. The best flowability behavior and the highest porosity value were observed in agglomerates containing the maltodextrin solution (Fuchs et al., 2006).

Turchiuli et al. (2005) also used the spray-drying methods and obtained spherical oil powders $(32 \pm 8 \mu \mathrm{m})$. After wet agglomeration, the particles were observed to have an irregular shape and a diameter of approximately $200 \mu \mathrm{m}$. The agglomerates had lower bulk and tapped densities values, and their porosity values were higher than those of powders. The wettability time was determined as 28 minutes for the initial powder products and only 3 minutes after the agglomeration process. Furthermore, the spray-dried powders exhibited poor flow characteristics, but the agglomeration process helped to improve the particle size and the flowability of the powder products and reduced the stickiness.

Maronga and Wnukowski (1998) measured the air temperature distribution by changing the parameters of the amount of model water $(250,500,750 \mathrm{gr})$, inlet air temperature $\left(60,70,80^{\circ} \mathrm{C}\right)$, and air pressure $(1,2,3$ bar $)$. The air temperatures in the active wetting zone (the portion of the fluidized bed that soaks the solid particles of the sprayed fluids) was below $40^{\circ} \mathrm{C}$ at a constant inlet air temperature $\left(60-80^{\circ} \mathrm{C}\right)$. The size and shape of the area from which the agglomerate was initiated were shown to influence the growth mechanism of the particles depending on the processing conditions (inlet air temperature, liquid feed rate, spray pressure, and particle load). Furthermore, pockets with high temperature and humidity were observed in the depths of the bed, the lowest air temperature was found in the area at the top of the bed just below the spray head, and the air temperature and humidity were very low for the fluid bed agglomeration process.

\section{Conclusions}

Very small particle sizes have a negative effect on the reconstitution properties of powders. To overcome this problem, agglomeration is used to improve the functional properties of the powders. During the agglomeration process, the powders cluster, increasing the particle size. Several agglomeration methods can be employed depending on the desired end-use properties of agglomerates. The fluidized bed agglomeration method is widely used in the industry since it produces agglomerates with high porosity and homogeneity. To prevent possible problems and achieve the desired products, the control mechanisms of the parameters affecting agglomeration; e.g., inlet air temperature, velocity, moisture content, mixing rate, and binder property must be investigated and controlled.

\section{References}

Barbosa-Canovas G.V., Rivas E.O., Juliano P., Yan, H. (2005) Size enlargement. Food Powders: Physical Properties, Processing and Functionality, Kluwer Academic/Plenum, New York, USA, 175-198.

Bouffard, J., Kaster M. and Dumont H., 2005, Influence of Process Variable and Physicochemical Properties on the Granulation Mechanism of Mannitol in a Fluid Bed Top Spray Granulator, Drug development and Industrial Pharmacy, 31 923-933.

Burggraeve A., Monteyne T., Vervaet C., Remon J.P. and Beer T.D. (2013) Process analytical tools for monitoring, understanding, and control of pharmaceutical fluidized bed granulation: a review. The Eurpean Journal of Pharmaceutics and Biopharmaceutics, 83 2-15.

Geankoplis C. J. (2003) Transport processes and separation process principles:(includes unit operations). Prentice Hall Professional Technical Reference.

Dewettinck K., Huyghebaert A. (1998) Top-spray fluidized bed coating: Effect of process variables on coating efficiency. LWT- Food Science and Technology, 31 568-575.

Fuchs M., Turchiuli C., Bohin M., Cuvelier M.E., Ordonnaud C., Peyrat-Maillard M.N., Dumoulin E. (2006) Encapsulation of oil in powder using spray drying and fluidised bed agglomeration. Journal of Food Engineering, 75 27-35.

Ghosal S., Indira T.N., Bhattacharya S. (2010) Agglomeration of a model food powder: Effect of maltodextrin and gum arabic dispersions on flow behavior and compacted mass. Journal of Food Engineering, 96 222-228.

Hafsa I., Mandato S., Ruiz T., Schuck P., Jeantet R., Mejean S., Chevallier S., Cuq B. (2015) Impact of the agglomeration process on structure and functional properties of the agglomerates based on the durum wheat semolina. Journal of Food Engineering, 145 25-36. 
Iveson S.M., Litster J.D., Hapgood K., Ennis B.J. (2001) Nucleation, growth and breakage phenomena in wet granulation processes: a review. Powder Technology, 117 3-39.

Jinapong N., Suphantharika M., Jamnong P. (2008) Production of instant soymilk powders by ultrafiltration, spray drying and fluidized bed agglomeration. Journal of Food Engineering, 84 194-205.

Knight P.C. (2001) Structuring agglomerated products for improved performance. Powder Technology, 119 14-25.

Kumar L., Pougatch K., Salcudean M., Grace, J., Grecov D., McMillan J. (2017) Population balance modeling for the growth of agglomerates via primary and secondary agglomeration in gas-fluidized beds. Powder Technology, 321 499-513.

Liu L.X., Iveson S.M., Litster J.D., Ennis B.J. (2000) Coalescence of deformable granules in wet granulation processes. AIChE Journal, 46 529-539.

Litster J.D. and Ennis B.J. (2004) The Science and Engineering of Granulation Processes. Kluwer Powder Technology Series, Dordrecht.

Machado, V. G., Hirata, T. A. M., Menegalli, F. C. (2014) Agglomeration of soy protein isolate in a pulsed fluidized bed: Experimental study and process optimization. Powder Technology, 254 248-255

Maronga S.J., Wnukowski P. (1998) The use of humidity and temperature profiles in optimizing the size of fluidized bed in a coating process. Chemical Engineering Science, 37 423-432.

Palzer, S. (2005) The effect of glass transition on the desired and undesired agglomeration of amorphous food powders. Chemical Engineering Science, 60(14) 3959-3968.

Palzer S. (2007) Drying of wet agglomerates in a continuous fluid bed: Influence of residence time, air temperature and air-flow rate on the drying kinetics and the amount of oversize particles. Chemical Engineering Science, 62 463-470.

Palzer S. (2011) Agglomeration of pharmaceutical, detergent, chemical and food powders - similarities and differences of materials and processes. Powder Technology, 206 2-17.

Planinsek O., Pisek R., Trojak A., Srcic S. (2000) The utilization of surface free-energy parameters for the selection of a suitable binder in fluidized bed granulation. International Journal of Pharmaceutics, 207 77-88.

Rayo L.M., Carvalho L.C., Sarda F.A.H., Dacanal G.C., Menezes E.W., Tadini C.C. (2015) Production of instant green banana flour (Musa cavendischii, var. Nanicao) by a pulsedfluidized bed agglomeration. LWT - Food Science and Technology, 63 461-469.

Rohera B. D., Zahir A. (1993) Granulations in a fluidized-bed: Effect of binders and their concentrations on granule growth and modeling the relationship between granule size and binder concentration. Drug Development and Industrial Pharmacy, 19 773-792.

Saad M.M. Barkouti A., Rondet E., Ruiz T., Cuq B. (2011) Study of agglomeration mechanisms of food powders: Application to durum wheat semolina. Powder Technology, 208 399-408.

Saleh K., Guigon P. (2009) Mise en oe uvre des poudres. Techniques de granulation humide et liants. Techniques de l'ing é nieur J2 253 1-14.

Schuchmann H. (1995) Production of instant foods by jet agglomeration. Food Control, 6(2) 95-100.
Seo A., Holm P., Schaefer T. (2002) Effects of droplet size and type of binder on the agglomerate growth mechanisms by melt agglomeration in a fluidised bed. European Journal of Pharmaceutical Science, 16 95-105.

Teunou E., Poncelet D. (2002) Batch and continuous fluid bed coating - review and state of the art. Journal of Food Engineering, 53 325-340.

Turchiuli C., Fuchsa M., Bohina M., Cuvelierb M.E., Ordonnaudb C., Peyrat-Maillardb M. N., Dumoulina E. (2005) Oil encapsulation by spray drying and fluidised bed agglomeration. Innovative Food Science and Emerging Technologies, $629-35$

Turchiuli C., Smail R., Dumoulin E. (2012) Fluidized bed agglomeration of skim milk powder: Analysis of sampling for the follow-up of agglomerate growth. Powder Technology, In Press.

Turchiuli C., (2013) Fluidization in food powder production 8. In: Handbook of Food Powders, Woodhead Publishing Series in Food Science, Technology and Nutrition, AgroParisTech, France, 178-199.

Tuske Z., Regdon G., Eros I., Srcic S., Pintye-Hodi K. (2005) The role of the surface free energy in the selection of a suitable excipient in the course of a wet-granulation method. Powder Technology, 155 139-144.

Ziyani L., Fatah N. (2014) Use of experimental designs to optimize fluidized bed granulation of maltodextrin. Advanced Powder Technology, 25 1069-1075. 